\title{
COMPOSTAGEM DE RESÍDUOS DA INDÚSTRIA SUCROALCOOLEIRA ENRIQUECIDOS COM FONTES ALTERNATIVAS DE FÓSFORO
}

\begin{abstract}
AVALHÃES, Cintia Carla ${ }^{1}$ PRADO, Renato de Mello ${ }^{2}$
\end{abstract}

Recebido em: 2008-01-22

Aprovado em: 2009-04-05

ISSUE DOI: $10.3738 / 1982.2278 .161$

RESUMO: O setor sucroalcooleiro tem como subproduto a torta de filtro, que enriquecida com fósforo na forma de fosfato natural ou solúvel e na presença de microrganismos solubilizadores de fosfato poderá constituir como fertilizante organo-mineral alternativo. Diante disso, objetivou-se avaliar os efeitos do enriquecimento do composto orgânico de torta de filtro e cinza, com rocha fosfática (RF), fosfato monoamônio (MAP) e gesso, e na presença de microrganismos solubilizadores de fosfato (MSF) sobre a composição química do composto organomineral. $\mathrm{O}$ experimento foi instalado no delineamento de blocos ao acaso, contendo 8 tratamentos e 4 repetições, conforme segue: T1. composto a base de torta de filtro e cinza (CTFC) (testemunha); T2. CTFC + 5\% de RF + MSF; T3. CTFC + 5\% de RF; T4. CTFC + 10\% de RF + MSF; T5. CTFC + 10\% de RF; T6. CTFC + 1,25\% $\mathrm{MAP}+5 \%$ de RF + MSF; T7. CTFC + 1,25\% MAP + 5\% de RF; T8. CTFC + 5\% de RF + 5\% gesso + MSF. Houve monitoramento periódico da temperatura e umidade das leiras ( $15 \mathrm{~m}$ de comprimento) com os tratamentos. Durante a condução do experimento, foram realizadas três amostragens do composto, aos 20 , 40 e 60 dias após a incubação. Avaliaram-se os teores de $\mathrm{P}_{2} \mathrm{O}_{5}$ total e solúvel em ácido cítrico, bem como, valor do $\mathrm{pH}$, umidade, $\mathrm{K}_{2} \mathrm{O}, \mathrm{Ca}, \mathrm{Mg}, \mathrm{S}$, matéria orgânica (M.O.), cinzas e a densidade do composto. A compostagem da torta de filtro com cinza, enriquecida com 5\% de rocha fosfática e 1,25\% de MAP proporcionou maior teor de fósforo solúvel no composto. O uso de microrganismo solubilizadores de fosfato e de gesso não influenciou a solubilização da rocha fosfática.

Palavras-chave: Solubilização. Composto orgânico. Rocha fosfatada. MAP. Inoculante. Microrganismos.

\section{COMPOSTING FROM THE SUGAR-ALCOHOL FIELD WASTE ENRICHED WITH ALTERNATIVE SOURCES OF PHOSPHORUS}

SUMMARY: The sugar-alcohol field has as a by-product of the filter cake, which enriched with phosphorus in the form of rock phosphate or soluble and the presence of microorganisms solubilizing of phosphate fertilizer could be as organo-mineral alternative. Given this, it was aimed to assess the effects of enrichment of organic compound of the filter cake and gray, with rock phosphate (RF), monoamônio phosphate (MAP) and plaster, and the presence of microorganisms solubilizing of phosphate (MSF) on the composition chemical compound of organo-mineral. The experiment was installed in the design of blocks at random, containing 8 treatments and 4 replicates, as follows: Q1. composed the basis of the filter cake and gray (CTFC) (control); T2. CTFC $+5 \%$ of $\mathrm{RF}+\mathrm{MSF}$; T3. CTFC $+5 \%$ of RF; T4. CTFC $+10 \%$ of RF + MSF; T5. CTFC + 10\% of RF; T6. CTFC MAP + $1.25 \%+5 \%$ of RF + MSF; T7. CTFC MAP $+1.25 \%+5 \%$ of RF; T 8 . CTFC $+5 \%$ of RF $+5 \%+$ MSF plaster. There were periodic monitoring of temperature and humidity of compound with the treatments. During the conduct of the trial, there were three samples of the compound, 20, 40 and 60 days after hatching. Were evaluated on the levels of total $\mathrm{P}_{2} \mathrm{O}_{5}$ and soluble in citric acid, and $\mathrm{pH}$, humidity, $\mathrm{K}_{2} \mathrm{O}, \mathrm{Ca}, \mathrm{Mg}, \mathrm{S}$, organic matter $(\mathrm{OM})$, ash and density of the compound. Composting of the filter cake with gray, enriched with $5 \%$ of rock

1 Mestranda em Ciência do Solo, FCAV/UNESP. Via de Acesso Paulo D. Castellane, s/n. CEP. 14844900 - Jaboticabal-SP. E-mail: cintiavalhaes@ hotmail.com

$2 \quad$ FCAV/UNESP 
phosphate and $1.25 \%$ of MAP a higher level of phosphorus in soluble compound. The use of micro solubilizing of phosphate gypsum and did not influence the solubilization of the rock phosphate.

Keywords: Solubilization. Organic compound. Rock phosphate. MAP inoculant. Microorganisms.

\section{INTRODUÇÃOO}

Uma das formas viáveis de se utilizar resíduos agroindustriais é através da compostagem, objetivando o tratamento desta matéria-prima e a reciclagem da matéria orgânica, devolvendo-a ao meio ambiente na forma de fertilizante orgânico, que apresenta um menor custo em relação aos fertilizantes sintéticos.

A torta de filtro é um dos principais resíduos gerados pela atividade agroindustrial sucroalcooleira (CARNEIRO, 2004), e são gerados, em média, $40 \mathrm{~kg}$ de torta de filtro por tonelada de cana processada (COOPERSUCAR, 1995). Porém, para melhorar as características do produto recomenda-se o tratamento do mesmo, embora os fertilizantes organominerais apresentem baixas concentrações de nutrientes, especialmente fósforo.

O fósforo geralmente é encontrado nos solos na forma de fosfato tricálcico $\left[\mathrm{Ca}_{3}\left(\mathrm{PO}_{4}\right)_{2}\right]$, é insolúvel e, portanto, não disponível para as plantas. Além disso, pode ocorrer na forma de compostos orgânicos fosforados e, finalmente, na forma de solúvel $\left(\mathrm{H}_{2} \mathrm{PO}_{4}{ }^{-}\right)$, entretanto, apresenta elevada perda no solo, devido as reações químicas de adsorção, diminuindo sua disponibilidade às plantas (BRANCO et al., 2001).

Os fertilizantes fosfatados mais utilizados na agricultura são solúveis (em água ou citrato neutro de amônio) e requerem enxofre elementar e concentrados apatíticos de elevada qualidade para produção, conduzindo a subutilização dos depósitos de fosfato (perdas elevadas de $\mathrm{P}$ no beneficiamento), consequentemente é necessário estudar as fontes alternativas de fósforo (BENEDITO, 2007), sustentáveis que não utilizem o processo industrial que requer elevado gasto de energia. Neste sentido, um forma alternativa de produção de fertilizantes fosfatados seria o uso do processo biológico a partir de microorganismos solubilizadores de fosfato. Neste contexto, destaca-se o papel dos microrganismos na solubilização desses compostos fosforados. Existem basicamente, duas formas de contribuição por parte dos microrganismos para a solubilização do fósforo: uma através da atividade secretora especifica que transformam os compostos fosforados em formas de assimilação fácil e imediata; e outra através da presença de $\mathrm{CO}_{2}$ em excesso no meio, que se combina com o fosfato tricálcico, insolúvel, formando o fosfato bicálcico, solúvel. 
Neste sentido, todos os fatores que influenciam a atividade dos microrganismos iria afetar o processo biológico de produção dos fertilizantes fosfatados. Entre os fatores ambientais, o tipo de fosfato e a fonte de C estão entre os mais estudados (SILVA FILHO; VIDOR, 2000). No entanto, a fonte de $\mathrm{N}$ e teores de nutrientes inorgânicos podem ter importância significativa na solubilização dos fosfatos. $\mathrm{O}$ efeito da fonte de $\mathrm{N}$ tem sido relacionado ao balanço de íons absorvidos (FERNANDES; SOUZA, 1990). De modo geral, a solubilização aumenta com a absorção de fontes amoniacais e diminui com as nítricas. Com a absorção de amônio, a célula tem que promover a extrusão de prótons $\left(\mathrm{H}^{+}\right)$para manter a sua eletroneutralidade e o transporte ativo secundário em funcionamento (FERNANDES; SOUZA, 1990), acidificando o meio e conseqüentemente solubilizando o fosfato.

O cálcio também pode afetar a solubilização do fosfato. O Ca como nutriente é necessário à atividade enzimática e à estrutura da membrana (GRIFFIN, 1994), e sua deficiência favorece a solubilização de fosfatos deste elemento (ROBINSON; SYERS, 1990). Cunningham; Kuiack (1992) verificaram que Penicillium bilaji, em altas concentrações de Ca, esporula e passa a alcalinizar o meio, ao passo que, em baixas concentrações, produz ácidos. Existem trabalhos que indicam a influência positiva do teor de matéria orgânica sobre a solubilização do fosfato de rocha (BRAMS, 1973; MINHONI et al., 1991).

Diante disso, pesquisas têm sido realizadas com intuito de se melhorar esse processo visando aumentar o fornecimento de fósforo para as plantas, pelo uso de fertilizantes orgânicos enriquecidos com inoculantes (fungos e bactérias), produzindo um composto organo-mineral. Assim, existe grande potencial agronômico para uso desses fertilizantes na agricultura (KIEHL, 1985).

Com o presente trabalho, objetivou-se avaliar os efeitos do enriquecimento do composto orgânico de torta de filtro e cinza, com rocha fosfática (RF), fosfato monoamônio (MAP) e gesso, e na presença de microrganismos solubilizadores de fosfato (MSF) sobre a composição química do composto organo-mineral.

\section{MATERIAL E MÉTODOS}

O experimento foi instalado a campo, em pátio de compostagem (a céu aberto), constituído por 8 tratamentos, conforme segue: T1. composto a base de torta de filtro e cinza (CTFC) (Testemunha); T2. CTFC $+5 \%$ de rocha fosfática $(\mathrm{RF})+$ microrganismos solubilizadores de fosfato (MSF); T3. CTFC + 5\% de RF; T4. CTFC + 10\% de RF + MSF; T5. CTFC $+10 \%$ de RF; T6. CTFC $+1,25 \% \mathrm{MAP}+5 \%$ de RF + MSF; T7. CTFC $+1,25 \%$ 
MAP $+5 \%$ de RF; T8. CTFC $+5 \%$ de RF $+5 \%$ gesso + MSF. Utilizou-se o delineamento de blocos ao acaso em 4 repetições. A fonte de fósforo foi a rocha fosfática fosforita natural $\left(\mathrm{P}_{2} \mathrm{O}_{5 \text { total }}=24,8 \% ; \mathrm{P}_{2} \mathrm{O}_{5 \text { solúvel }}=8,2 \% ; \mathrm{CaO}=20,75 \% ; \mathrm{S}=0,43 \%\right.$; e $\left.\mathrm{pH}=5,9\right)$ e outra fonte solúvel, o fosfato monoamônio (MAP) $\left(\mathrm{P}_{2} \mathrm{O}_{5}\right.$ solúvel=50\% e $\left.\mathrm{N}=10 \%\right)$. O inoculante utilizado contém os microorganismos solubilizadores de fosfato, enriquecido com ácidos orgânicos de baixo peso molecular, extratos vegetais, polissacarídeos e fosfato pruficado.

As parcelas foram constituídas de seções de leira de compostagem (aproximadamente $15 \mathrm{~m}$ de comprimento), sendo que cada leira representou um bloco (repetição).

As características químicas do composto puro (torta + fuligem), foram as seguintes $(\mathrm{em} \%): \mathrm{M} . \mathrm{O}=42,56 ; \mathrm{P}_{2} \mathrm{O}_{5}$ total $=2,08 ; \mathrm{P}_{2} \mathrm{O}_{5}$ solúvel $=1,68 ; \mathrm{K}_{2} \mathrm{O}=0,81 ; \mathrm{Ca}=2,11 ; \mathrm{Mg}=0,66$; $\mathrm{S}=0,66 ;$ cinzas $=57,5 ;$ umidade $=65,7 . \mathrm{E}$ ainda, a relação $\mathrm{C} / \mathrm{N}=19 / 1 ;$ o $\mathrm{pH}=8,6$; e a densidade aparente $=0,31 \mathrm{~g} \mathrm{~cm}^{-3}$.

Os fertilizantes e o gesso foram aplicados em todas as leiras (de acordo com o tratamento) e um dia depois foi aplicado o inoculante sobre as leiras, conforme segue:

$1^{\circ}$ ) As leiras foram montadas a partir de torta de filtro + cinza, após a mistura (revolvimento com o compostador), aplicou-se rocha fosfática e misturou-se (revolvimento com o compostador), esta mistura chamamos de M1.

$2^{\circ}$ ) Com as leiras prontas (M1), iniciou-se o preparo do tanque para a multiplicação do inóculo, num substrato contendo torta de filtro, fosfato de rocha, água e o inoculante (microrganismos solubilizadores de fosfato).

O material permaneceu aerando por 12 horas, esta mistura foi denominada M2.

A mistura M2 foi aplicada às leiras pré-confeccionadas (M1), com distribuidor utilizado para esterco líquido. Procedeu a incorporação do aditivo com o compostador imediatamente após a aplicação. Esta mistura foi denominada M3.

M1 (M.O. + F.R.) + M2 (Ad. + M.O.+ FR + água) $\rightarrow$ M3 (leira inoculada) Onde: Ad.: aditivo ou inoculante biológico; M.O.: material orgânico (torta de filtro); e F.R: fosfato de rocha.

A caixa de aeração foi montada com o aerador no fundo, objetivando uma aeração mais uniforme, sendo o inóculo foi o último constituinte a ser adicionado na caixa.

O material oriundo da caixa de aeração foi adicionado no topo da leira e logo em seguida misturado utilizando o equipamento compostador, visando sempre uma boa mistura do aditivo com o volume da leira (homogeneização). 
Foram realizados cinco revolvimentos das leiras durante o processo, em função do controle de temperatura e umidade, utilizando o equipamento compostador. Para tanto, foi realizado monitoramento de temperatura, a cada dois ou três dias, e umidade a cada cinco dias e/ou após chuvas. O revolvimento da leira ocorria quando se constatava, em média, uma temperatura acima de $60^{\circ} \mathrm{C}$ e umidade acima de $50 \%$, visando manter as condições de ambiente propícias para a atividade das bactérias.

Foram coletadas 10 subamostras que, depois de homogeneizadas, obtendo-se uma amostra composta de cada parcela, nas seguintes épocas: antes da incubação, 20 dias, 40 dias e 60 dias após a incubação.

Realizou-se a análise química do composto, determinando-se os teores de fósforo total e fósforo solúvel em ácido cítrico, bem como, $\mathrm{pH}, \mathrm{K}_{2} \mathrm{O}, \mathrm{Ca}, \mathrm{Mg}$, $\mathrm{S}$, matéria orgânica (M.O), cinzas, e ainda, a umidade e a densidade. E também calculou-se a taxa de solubilização (SOL.), considerando o teor de fósforo solúvel em função do teor de fósforo total.

Em seguida realizou-se a análise de variância pelo teste $\mathrm{F}$ para todas variáveis em estudo e para comparação das média aplicou-se o teste de Tukey $(\mathrm{p}<0,05)$, utilizando o software SAS INSTITUTE (1996).

\section{RESULTADOS E DISCUSSÃO}

Os tratamentos apresentaram diferença significativa nas variáveis analisadas, exceto o teor de $\mathrm{K}_{2} \mathrm{O}$ e $\mathrm{Mg}$ aos 20 dias após a incubação e a densidade em todos os períodos de incubação (Tabela 1).

Observou-se efeito significativo para os teores de $\mathrm{P}$ total e de $\mathrm{P}$ solúvel em acido cítrico, em função dos tratamentos (Tabela 1). Como era esperado, a aplicação de fósforo no composto aumentou o teor desse nutriente. Nota-se que a aplicação da rocha fosfatada na maior concentração $(10 \%)$ e do MAP e a rocha fosfatada a 5\%, resultaram em maior teor de P total no composto em todas as épocas de amostragem, entretanto, para o teor de $\mathrm{P}$ solúvel destacou-se apenas os tratamentos com emprego do MAP em todas as épocas de amostragem, exceto os 60 dias após a incubação que o MAP sem aplicação dos microrganismos solubilizadores não diferiu do uso da rocha fosfatada a 10\% (Tabela 1).

Observa-se, de forma geral, os teores de P solúvel médios, aos 20, 40 e 60 dias, foram de 3,6; 3,9 e 2,4\%, respectivamente (Tabela 1). Nota-se que aos 40 dias após incubação teve o maior teor médio de $\mathrm{P}$ solúvel. Com isso, podemos inferir que não existe necessidade 
de se estender o processo de compostagem até 60 dias, o que pode diminuir os custos de produção do composto.

Esse efeito positivo do MAP possivelmente é explicado pela presença de uma fonte de $\mathrm{N}$ amoniacal. Pois, com a absorção de amônio, a célula tem que promover a extrusão de prótons $\left(\mathrm{H}^{+}\right)$para manter a sua eletroneutralidade e o transporte ativo secundário em funcionamento (FERNANDES; SOUZA, 1990), acidificando o meio e conseqüentemente solubilizando o fosfato.

Observa-se que a presença ou ausência do inoculante nos tratamentos com aplicação do P seja como rocha fosfatada (concentração de 5 ou 10\%) ou do MAP, não diferiram entre si. Portanto, a adição do inoculante não aumentou a solubilização de fósforo do composto, o que discorda dos resultados de Branco et al. (2001) que afirmam que a atividade microbiana (fungos e bactérias) permite a solubilização da rocha fosfática nos processos de compostagem de resíduos agropecuários.

A ação das bactérias na solubilização de $\mathrm{P}$ pode ser influenciado por diversos fatores como como $\mathrm{pH}$, temperatura e umidade, natureza do composto orgânico (torta de filtro e cinza) ou mesmo das estirpes das bactérias que são sensíveis às alterações do meio.

A hipótese do valor $\mathrm{pH}$ sobre a atividade dos microrganismos é discutível, pois de forma geral o valor $\mathrm{pH}$ médio obtido no presente trabalho, foi de 7,2 aos 20 dias; 7,4 aos 40 dias; e 6,3 aos 60 dias encontrando-se dentro da faixa adequada sugerida por Pereira Neto (1989) $(5,5$ a 8,0), entretanto, o alto valor de $\mathrm{pH}$, beneficia as bactérias solubilizadores de fosfato, em detrimento aos fungos, e como esses últimos são mais eficientes na solubilização de fosfato de rocha (SOUCHIE ABBOUD, 2007), o que poderia ter contribuído para a ausência de efeito dos microrganismos solubilizadores de fosfato (inoculante) no aumento do teor de P solúvel do composto.

Além disso, um outro fato poderia diminuir a eficiência dos solubilizadores de fosfato seria a liberação de metais tóxicos da rocha fosfática utilizada, afetando o desenvolvimento, a fisiologia e o metabolismo dos solubilizadores de fosfatos como fungos (KARAMUSHKA et al., 1996) ou bactérias (DI SIMINE et al., 1998).

Nota-se que a temperatura média durante o processo de compostagem, variou entre $58^{\circ} \mathrm{C} ; 47^{\circ} \mathrm{C}$ e $45^{\circ} \mathrm{C}$, aos 20, 40 e 60 dias após incubação, respectivamente (Figura 1), portanto estando na faixa considerada adequada (40 e $60{ }^{\circ} \mathrm{C}$ ) (MALHEIROS, 1996) para atividade ótima dos microrganismos durante a compostagem. $\mathrm{E}$ da mesma forma ocorreu para a umidade do composto, não havendo diferença entre a mesma no composto com a presença e 
ausência do inoculante para as diferentes fontes ou doses de fósforo utilizadas no enriquecimento do composto.

A umidade média do composto foi de 53\% (20 dias), 55\% (40 dias) e diminuiu para 45\%, aos 60 dias (Tabela 1). Nota-se que a umidade média do composto ao longo do período experimental não limitado o processo da compostagem. Pois é sabido, que a umidade muito alta, maior que 65\%, a água ocupa os espaços vazios da massa, impedindo a livre passagem do oxigênio, causando condições de anacrobiose; e teores muito baixos, menores que 40\%, inibem a atividade microbiológica, diminuindo a taxa de estabilização; assim o teor ideal que situar-se ao redor de 55\% (PEREIRA NETO, 1989).

Nota-se que a taxa de solubilização do composto puro sem adição de $\mathrm{P}$, foi a maior tanto aos 20 dias $(82,7 \%)$ e aos 40 dias $(84,7 \%)$, comparado aos demais tratamentos com adição de $\mathrm{P}$ (Tabela 1). Como o teor inicial de $\mathrm{P}$ é muito baixo no composto puro comparado com os demais tratamentos com adição de $\mathrm{P}$, e como a mineralização do composto puro, representa proporcionalmente alta taxa de solubilização. Por outro lado, com fornecimento de $\mathrm{P}$ no composto, tem-se que a taxa de solubilização de fosfatos por bactérias é diminuída progressivamente, à medida que aumenta a concentração do material solubilizado no meio, até estacionar em um certo valor (BRANCO et al., 2001). Na literatura trabalhos em solo têm indicado que a medida que aumenta o teor de $\mathrm{P}$ solúvel é afetado o número de microorganismos (NUENBERG; VIDOR; STAMMEL, 1984) e tendo menor atuação dos microorganismos solubilizadores de fósforo (BERNARDES; SANTOS, 2006).

O percentual de solubilização de fósforo no controle (torta + fuligem) foi maior quando comparado aos compostos que receberam tratamento, tanto aos 20 dias $(82,7 \%)$, aos 40 dias $(84,7 \%)$ como aos 60 dias após a incubação $(78,5 \%)$ (Tabela 1). Portanto, a quantidade de $\mathrm{P}$ total presente no controle era muito pequena, sendo que a mínima quantidade de fósforo que fosse solubilizada representaria um percentual elevado. Porém, há relatos de que o composto inoculado com uma espécie bacteriana de alta capacidade solubilizadora de fósforo, demonstra uma atividade biológica e uma densidade de microrganismos ativos menor que o composto, onde não foi adicionado qualquer inóculo ou rocha fosfática e, isolando esses microrganismos, observa-se que essas bactérias formam um halo de inibição característico da produção de antibióticos, o que poderia explicar a estabilidade do teor de fósforo solúvel, mesmo na presença do inóculo (BRANCO et al., 2001).

Observa-se que a solubilização do P foi inferior no composto contendo gesso (T8) quando comparado ao tratamento semelhante que não recebeu gesso (T2), enriquecido com mesma quantidade de P (5\% de fosforita), sendo que os percentuais no composto sem e com 
gesso, aos 20, 40 e 60 dias, foram, respectivamente: 50,7 e 45,7; 47,2 e 48,0; 45,7 e 55,7\% (Tabela 1). Portanto, a inclusão do Ca não afetou positivamente a solubilização do fosfato, o que discorda de Griffin (1994) e concorda com Robinson; Syers (1990).

Os teores de $\mathrm{K}_{2} \mathrm{O}$ e $\mathrm{Mg}$ apresentaram variações durante o processo de compostagem, porém observa-se que não sofreram influência por parte do inóculo, já que essa variação não foi significativa e ocorreu em todos os tratamentos (Tabela 1).

$\mathrm{O}$ teor de $\mathrm{Ca}$ foi maior nos tratamentos com composto e gesso e composto e rocha fosfática (a 10\%), especialmente na primeira amostragem do composto, e na segunda amostragem não houve diferença entre o composto com rocha 5 e $10 \%$ e na última amostragem o maior teor desse nutriente foi o tratamento com uso do gesso (Tabela 1). Notase que de forma geral houve maior teor de $\mathrm{Ca}$ no tratamento com gesso $(\mathrm{Ca}=24 \%)$ e com rocha fosfática $(\mathrm{CaO}=33 \%)$ devido a presença desse elemento na sua composição química.

Para o teor de $\mathrm{S}$, observou-se que o tratamento com emprego do gesso (T8) proporcionou maior teor desse nutriente no composto (Tabela 1), fato esperado devido a presença dele na composição química do gesso.

Nota-se que o tratamento com composto puro o teor de M.O. foi maior que nos demais tratamentos com enriquecimento com fontes de fósforo, exceto aos 60 dias que não houve diferença entre o tratamento com composto puro e com a rocha de fosfato $5 \%$ (T2) (Tabela 1). Observou-se portanto, de forma geral, que o enriquecimento do composto com uma fonte de fósforo, diminuiu a proporção de material orgânico em detrimento ao mineral, o que explicaria a diminuição no menor teor de matéria orgânica do composto.

O menor teor de cinza foi obtido com composto puro e o tratamento com a rocha a $5 \%$, comparado aos demais, exceto na amostragem aos 40 dias, que o composto puro foi o tratamento com menor teor de cinza (Tabela 1). De forma geral, observou-se que nos tratamentos com enriquecimento do composto com o fósforo ou gesso, uma pequena variação no teor de cinzas, tanto aos 20 dias (66 a 74\%), aos 40 dias (70 a 75\%) como aos 60 dias de incubação (72 a 77\%) (Tabela 1), o que possivelmente não tenha afetado a solubilização de P do composto.

\section{CONCLUSÃO}

A compostagem da torta de filtro com cinza, enriquecida com $5 \%$ de rocha fosfática e 1,25\% de MAP proporcionou maior teor de fósforo solúvel no composto.

O uso de microrganismo solubilizadores de fosfato e de gesso não influenciou a solubilização da rocha fosfática. 


\section{AGRADECIMENTOS}

A empresa Campestre Agrotecnologia (Processo 1175/07-Funep), pela bolsa de estudos concedida a primeira autora e o auxílio à pesquisa.

\section{REFERÊNCIAS}

ALCANTARA, R. M. C. M. Propriedades químicas e bioquímicas e suas inter-relações em solos sob vegetação de mata e campo adjacentes. 168f. 1995.Dissertação (Mestrado em Solos e Nutrição de Plantas) - Universidade Federal de Lavras, Lavras.

BARROTI, G.; NAHAS, E. População microbiana total e solubilizadora de fosfato em solo submetido a diferentes sistemas de cultivo. Pesquisa Agropecuária Brasileira, v.35, n.10, p.2043-2050, 2000.

BENEDITO, D. S. Eficiência agronômica de fontes alternativas de fósforo e modelo de predição do uso de fosfatos naturais. 127 f. 2007. Tese (Doutorado) - Escola Superior de Agricultura Luiz de Queiroz. Universidade de São Paulo. Piracicaba.

BERNARDES, C. M; SANTOS. M. A. População microbiana como indicadora de interferência de diferentes manejos de solos de cerrado com cultivo de soja. Bioscience Journal, v.22, n.2, p.7-16, 2006.

BRANCO, S. M.; MURGEL, P. H.; CAVINATTO, V. M. Compostagem: Solubilização biológica de rocha fosfática na produção de fertilizante organo-mineral. Engenharia Sanitária e Ambiental, v.6, n.3, p.115-122, 2001.

BRAMS, E. Soil organic matter and phosphorus relationships under tropical forests. Plant Soil, v.39, p.465-468, 1973.

BROOKES, P. C. The use of microbial parameters in soil pollution by heavy metals. Biology and fertility of soils, v.19, n.4, p.269-279, 1995.

CARNEIRO, R. G. et al. Indicadores biológicos associados ao ciclo do fósforo em solos de Cerrado sob plantio direto e plantio convencional. Pesquisa Agropecuária Brasileira, v.39, n.7, p.661- 669, 2004.

CHEN, Y. P. et al. Phosphate solubilizing bacteria from subtropical soil and their tricalcium phosphate solubilizing abilities. Applied Soil Ecology, v.34,p.33-41, 2006.

COOPERSUCAR. Inventário de resíduos sólidos na agroindústria sucroalcooleira. Piracicaba,22 p., 1995. (Relatório Técnico)

CUNNINGHAM, J. E.; KUIACK, C. Production of citric and oxalic acids and solubilization of calcium phosphate by Penicillium bilaii. Applied and Environmental Microbiology, v.58, n.5, p. 1451-1458, 1992. 
DI SIMINE, C. D.; SAYER, J. A.; GADD, G. M. Solubilization of zinc phosphate by a strain of Pseudomonas fluorescens isolated from a forest soil. Biology and Fertility of Soils, v.28, p.87-94, 1998.

FERNANDES, M. S.; SOUZA, S. R. A aquisição de N por plantas. In: SIMPÓSIO BRASILEIRO SOBRE NITROGÊNIO EM PLANTAS, 1., 1990, Itaguaí. Anais... Itaguaí: Unicamp, p.172-192, 1990.

GRIFFIN, D. H. Fungal physiology. 2. ed. New York: Wiley-Liss,458 p., 1994.

JORGE, J. A. Solo, manejo e adubação. Melhoramentos. São Paulo. 1969.

KARAMUSHKA, V. I.; SAYER, J. A.; GADD, G. M. Inhibition of $\mathrm{H}^{+}$efflux from Saccharomyces cerevisiae by insoluble metal phosphates and protection by calcium and magnesium: inhibitory effects a result of soluble metal cations? Mycological Research, v.100, p. 707-413, 1996.

KIEHL, E. J. Fertilizantes orgânicos. Piracicaba: Agronômica Ceres,492 p. 1985.

MADSEN, E. L. Impacts of agricultural practices on subsurface microbial ecology. In: SPARKS, D. L. (Ed.). Advances in Agronomy. San Diego: Academic Press. v. 54, p. 1-67. 1995.

MALHEIROS, S. M. P. Avaliação do processo de compostagem utilizando resíduos agroindustriais. 264 f. 1996. Dissertação (Mestrado). Faculdade de Engenharia da Unicamp..

MALHEIROS, S. M. P. Utilização de resíduos agroindustriais no processo de compostagem. In: CONGRESSO BRASILEIRO DE ENGENHARIA SANITÁRIA E AMBIENTAL, 19. ABES, III - 069. Anais... 1, p.1-8. 1997.

MINHONI, M. T. A.; CARDOSO, E. J. B. N.; EIRA, A. F. Efeito dos cinco tipos de matéria orgânica na solubilização microbiana de fosfato de rocha. Revista Brasileira de Ciência do Solo, v.15, p.29-35, 1991.

NAHAS, E. Soil microorganisms phosphatase products in different agricultural systems. Bragantia, v. 61,n.3, p. 352-357, 2002.

NAHAS, E.; ASSIS, L. C. Efeito da adição ao solo de fosfato solúvel obtido por via microbiológica a partir de fluorapatita. Revista Latinoamericana de Microbiologia, v. 33, n.2, p. 225-229, 1991.

NUENBERG, N. J.; VIDOR, C.; STAMMEL, J. G. Efeito de sucessões de culturas e tipos de adubação na densidade populacional e atividade microbiana do solo. Revista Brasileira de Ciência do Solo, v.8, n.2, p.197 - 203, 1984.

PEREIRA NETO, J. T. Conceitos modernos de compostagem. Engenharia Sanitária, v.28, n.2, p.104-109, 1989.

ROBINSON, J. S.; SYERS, J. K. A critical evaluation of the factors influencing the dissolution of Gafsa phosphate rock. Journal of Soil Science, v.41, n.4, p.597-605, 1990.

Nucleus, v.6, n.1, abr. 2009 
SAGARDOY, M. A.; SALERNO, C. M. Number, distribution, and characterization of heterotrophic bacteria in some Argentine soils. Anales de Edafologia y Agrobiologia, v. 42, p. 2069-2081, 1983.

SAS INSTITUTE. The SAS-system for windows: release 6.11 (software). Cary: Statistical Analysis System Institute. 1996.

SILVA FILHO, G. N.; VIDOR, C. Solubilização de fosfatos por microrganismos na presença de fontes de carbono. Revista Brasileira de Ciência do Solo, v. 24, n. 2, p. 311-319,2000.

SOUCHIE, E. L.; ABBOUD, A. C. S. Solubilização de fosfato por microrganismos rizosféricos de genótipos de guandu cultivados em diferentes classes de solo. Semina,v. 28, n.1, p.11-18, 2007.

VIDAL, M. F.; SANTOS, J. A. N; SANTOS, M. A. Setor Sucroalcooleiro no Nordeste Brasileiro: Estruturação da cadeia produtiva, produção e Mercado. In: CONGRESSO DA SOCIEDADE BRASILEIRA DE ECONOMIA E SOCIOLOGIA RURAL, 44.Anais... Fortaleza.2006. 
Tabela 1. Análise química do composto, em função dos tratamentos, aos 20, 40 e 60 dias após a incubação

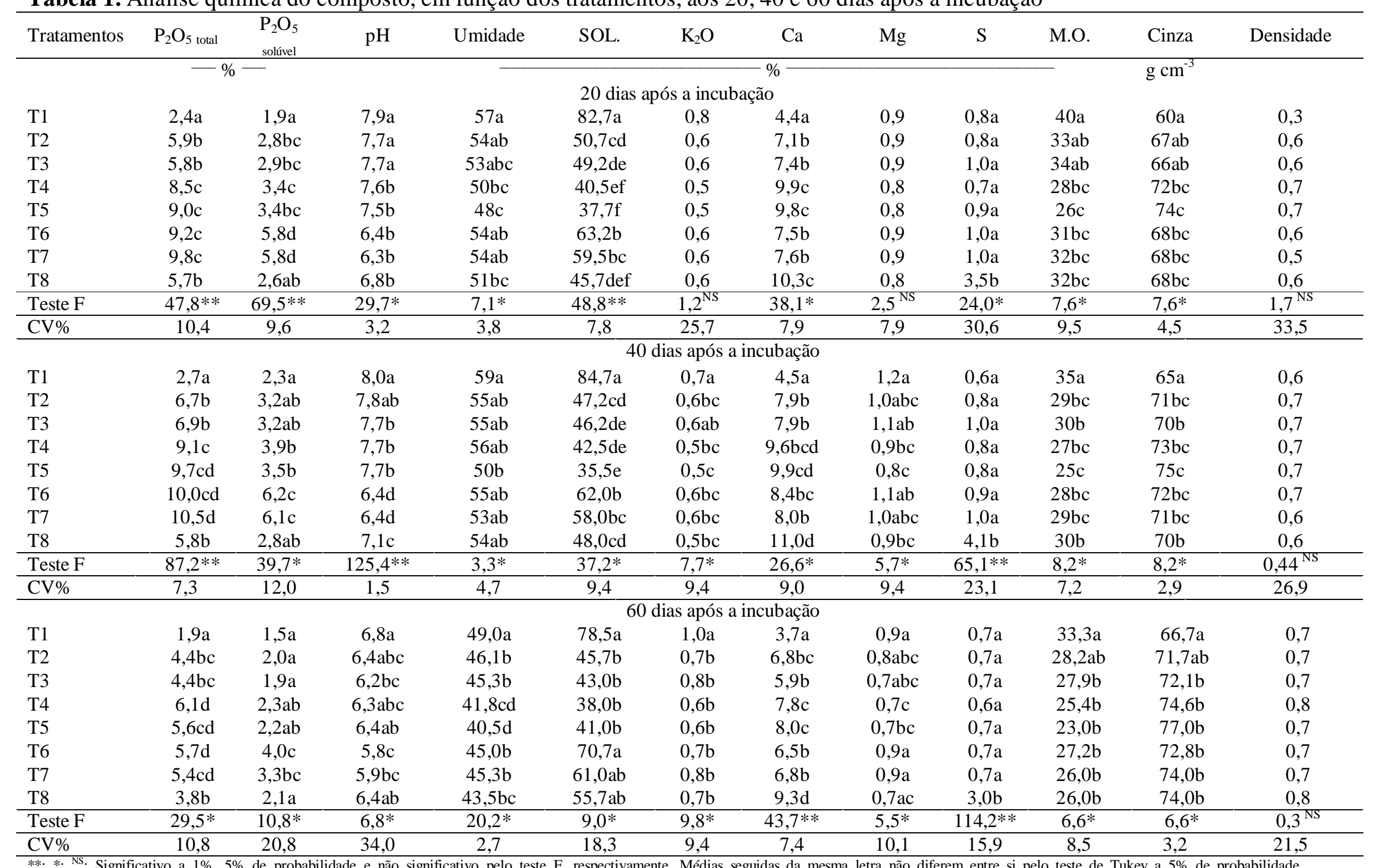




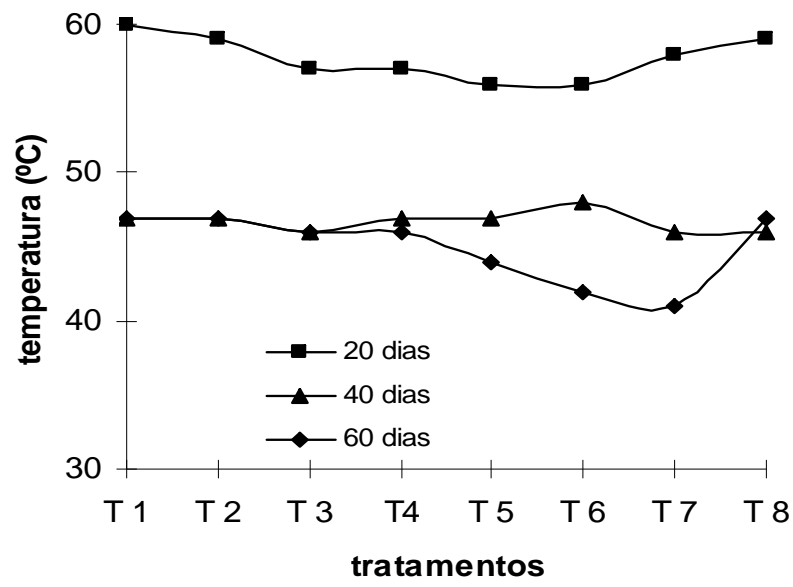

Figura 1. Temperatura média das leiras do composto, em função dos tratamentos, durante o processo de compostagem (20, 40 e 60 dias após a incubação). 
